\title{
AI CLASSROOM ANALYSIS SYSTEM FOR LANGUAGE TEACHING DEVELOPMENT
}

\author{
Hiroki Ishizuka ${ }^{1}, \&$ Akio Onishi ${ }^{2}$ \\ ${ }^{1}$ Hokkaido University of Education (Japan) \\ ${ }^{2}$ Version 2 Inc (Japan)
}

\begin{abstract}
One of the highly validated language classroom observation methods is Communicative Orientation of Language Teaching initiated by N. Spada and M. Fröhlich. This method, however, is not widely used by language teachers because of its time-consuming coding procedures. To overcome this shortcoming, the authors developed a new portable language classroom analysis tool named Mobile COLT and have started to plan its automatic version. Mobile COLT facilitates real-time class analysis using a Windows tablet. Since it can quantitatively display the features of the class, Mobile COLT can be an innovative tool for language teacher development. Its manual version has been already constructed, and the research to examine its effectiveness has been conducted in primary and secondary schools. This paper expounds the functions of Mobile COLT, the application in classroom practices, and the development of the automatic version of Mobile COLT.
\end{abstract}

Keywords: AI, language teacher development, automatic classroom analysis, COLT.

\section{Introduction}

Second language class observation studies were started to examine the features of language classes, focusing on not only learners but also teachers, and to investigate how their actual classes reflected SLA theories and teaching methodological theories. Since the late 19th century, various observation schemes have been invented and they have been used in numerous language classes. In 1995, after going through a period of trial and error, the scheme known as COLT (Communicative Orientation of Language Teaching) was introduced by N. Spada and M. Fröhlich. However, there has been a barrier to the widespread use of COLT by instructors and teachers. This barrier is the time-consuming process of segmenting classes into several different activities and episodes, then coding their features by rewinding a video clip again and again, and finally calculating the rates of features coded. In the early 21 st century, Web 2.0 technology has enabled us to interact with web pages, making it possible to conduct distance online teaching and learning in collaborative modes on a common virtual platform. Using this technology, the authors of this article expected that the barrier of using COLT would be overcome and it would be possible to provide researchers, instructors and teachers with an innovative, handy tool for assessing language classes. Thus the development of a new video-on-demand platform equipped with class analysis function was started in 2012. It was completed in the spring of 2014. Moreover, based on similar technology, a portable class analysis system was developed together with a simplified version of COLT coding system. It was named Mobile COLT and this newly developed system was expected to be effective in language teacher development. Studies were conducted in primary and secondary schools to confirm its effectiveness. Then, in 2018, the authors started to work on the automation of Mobile COLT to facilitate recording and the process of COLT analyzation. This newly designed system will enable language teachers to reflect on their own practices without the help of observers or coders. This paper expounds the development of the systems with its theoretical background, and its unique features.

\section{Background}

\subsection{COLT}

Interaction analysis of second language classes has been conducted for more than a half century. The Flanders System, the Jarvis System, and the Stirling Project System were developed from 1967 to 1981, and based on the results of such research, Fujimori (1990) proposed his original observation system 
containing analysis units such as Act, Move, Exchange and categories such as Speaking, Content \& Topic. His method was to analyze a class into segments and categorize them according to their features. COLT observation scheme proposed by N. Spada and M. Fröhlich adopted a similar method, with a more theoretically reliable background. They developed it to examine if a language class reflects the Communicative Language Teaching (CLT) theories. COLT consists of two parts: Part A for quantitative analysis and Part B for qualitative analysis (Spada \& Fröhlich, 1995). Part A has five categories or features: Participant Organization, Content, Content Control, Student Modality, and Materials, and each category has several subcategories, for example, Listening, Speaking, Reading, Writing, Others for Student Modality (language skills), according to which each segment of a class called activity and episode is identified and coded. Table 1 is the coding format for the original COLT Part A. In this scheme, classes containing Group Work, activities with more meaning-focused Content (Management and Message), Student Control, and Extended (discourse) Material are considered more communicative.

Table 1. COLT Part A coding scheme.

\begin{tabular}{|c|c|c|c|c|c|c|c|c|c|c|c|c|c|c|c|c|c|c|c|c|c|c|c|c|c|c|c|c|c|c|}
\hline \multicolumn{7}{|c|}{$\begin{array}{l}\text { PARTICIPANT } \\
\text { ORGANIZATION }\end{array}$} & \multicolumn{8}{|c|}{ CONTENT } & \multicolumn{3}{|c|}{$\begin{array}{l}\text { CONTENT } \\
\text { CONTROL }\end{array}$} & \multicolumn{5}{|c|}{$\begin{array}{l}\text { STUDENT } \\
\text { MODALITY }\end{array}$} & \multicolumn{8}{|c|}{ MATERIALS } \\
\hline \multicolumn{3}{|c|}{ Class } & \multicolumn{2}{|c|}{ Group } & \multicolumn{2}{|c|}{ Indivdual } & \multicolumn{2}{|c|}{$\begin{array}{c}\text { Manage- } \\
\text { ment }\end{array}$} & \multicolumn{4}{|c|}{ Language } & \multicolumn{2}{|c|}{$\begin{array}{l}\text { Other } \\
\text { topics }\end{array}$} & \multirow[b]{2}{*}{ 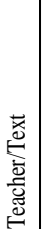 } & \multirow[b]{2}{*}{ 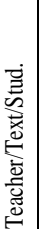 } & \multirow[b]{2}{*}{ 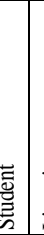 } & \multirow[b]{2}{*}{ 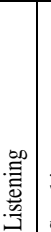 } & \multirow[b]{2}{*}{ 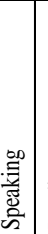 } & \multirow[b]{2}{*}{ 些 } & \multirow[b]{2}{*}{ 㴔 } & \multirow[b]{2}{*}{ 怘 } & \multicolumn{4}{|c|}{ Type } & \multicolumn{4}{|c|}{ Source } \\
\hline 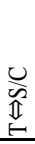 & 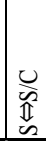 & $\begin{array}{l}\text { 퓸 } \\
\text { 일 }\end{array}$ & 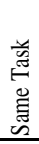 & 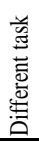 & 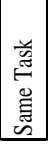 & 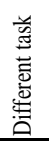 & 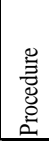 & 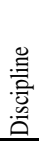 & 志 & 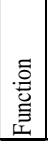 & 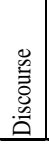 & 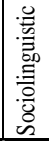 & 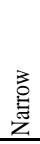 & $\begin{array}{l}\mathscr{\mathscr { g }} \\
\stackrel{\mathscr{D}}{\circ} \\
\end{array}$ & & & & & & & & & 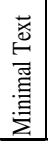 & 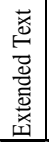 & 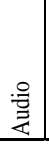 & $\begin{array}{l}\text { 吾 } \\
\text { 吾 } \\
\end{array}$ & $\begin{array}{l}n \\
\sum_{1} \\
\\
\end{array}$ & 兊 & 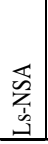 & 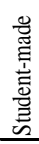 \\
\hline
\end{tabular}

After this scheme was invented, a considerable number of studies focusing on CLT have utilized it and attempted to examine its usefulness and validity. It has been confirmed that COLT can be used as a tool for clarifying language class features; such as the change of activity contents in longitudinal studies (Sugino, Koga, \& Kawashima, 2004), the occurrence of negotiation of meaning and corrective feedback (Panova \& Lyster, 2002; Ahlem \& Spada, 2006), and the efficiency of L2 use (Yamada, 1996).

\subsection{Lesson studies}

"Lesson Study" is defined as studies of actually conducted school classes. The typical type of lesson study at school consists of a demonstration class given by a teacher followed by a meeting of reflection on the performed lesson by observer teachers. The term lesson study was first used in 1999 by Makoto Yoshida in his doctoral dissertation. (cited in Takahashi \& Yoshida, 2004). The origins of lesson study can be traced back to the early 1900s' when study meetings about new teaching methods took place in attached schools and private schools (Nakatome, 1984). Lesson study was established as a strategy of in-service training by the middle of the 1960s (Fernandez \& Yoshida, 2004). It was first used by Mathematics teachers.

Lesson Study has been introduced in many different countries such as in the US, the Netherlands, South Africa, and Bangladesh. Although the English proficiency of Japanese young people is not sufficiently high, the tradition of lesson studies has also been passed on to Japanese English teachers, and English lessons at school have been studied in many different ways. However, the lesson studies which have been conducted to date, including those in mathematics and science, generally take a qualitative approach based on impressive discussions among participants. They are not based on objective quantitative data, and therefore they cannot provide teachers with clear and reliable guidelines to improve their teaching.

As mentioned above, COLT can provide language teachers with quantitative data of the conducted class. If COLT can be used in language classrooms and the analysis results can be shown without delay after the class is over, it would be a powerful tool to add an objective perspective to lesson studies, which have been rather subjective in nature, and this integration of objective and subjective perspectives might have the potential to help reform language classes drastically.

\section{Development of CollaVOD}

Based on the COLT scheme, the authors started to develop a VOD (Video-on-Demand) system equipped with functions needed to analyze a class. It was named CollaVOD. Two major developments have been realized. One was an asynchronous communication tool to discuss a filmed class collaboratively from different locations, and another was a class analysis tool devised to code interactions between a teacher/student(s) and student(s) occurring in a class according to COLT coding scheme. When this tool is used while a course creator makes online VOD material in a virtual classroom, users can use 
COLT to analyze the class when they log in to the class. They first decide where to start and end one episode of an activity, for example, a greeting at the start of the lesson lasting two minutes. Then they start coding the episode by checking proper categories of COLT that correspond to the features of the episode (Figure 1). The process is repeated until all the coding is completed, in other words, until the class time ends. This tool was also equipped with the function of automatic calculation of distributional rates within and across COLT categories. The coding procedure itself is the same as coding on a paper with a pen, but there are quite a few advantages of using this system as follows:

1. Coding work can be done collaboratively from distant locations either asynchronously or synchronously.

2. Teachers can check the features of their classes by observing graphical images and their Global Scores, which is an index of communicativeness of a language class, soon after the coding is completed.

3. It has the function of creating new COLT categories and revising the coding system with high flexibly, which enables researchers to explore and propose a different class assessment scheme.

Figure 1. Procedure of Manual COLT Coding on CollaVOD.

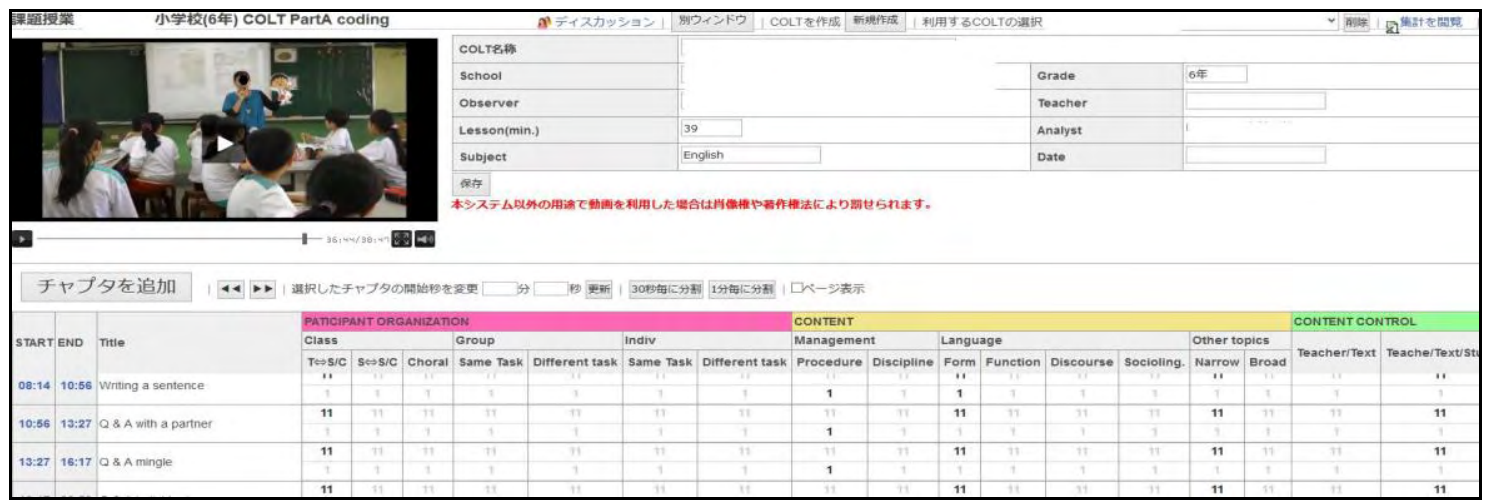

\section{Development of mobile COLT}

After confirming the efficiency of CollaVOD, the authors started to develop the mobile version of COLT analysis system. This version was planned and constructed in a way that would allow a language class observer to carry it into the class and analyze the class while he/she is observing and recording it. The development was completed in 2016 and was named Mobile COLT. Mobile COLT uses categories revised from those of the original COLT of Spada and Fröhlich (1995). Table 2 shows the newly adapted categories. With these new categories, observers can code the segments of a class far more easily and quickly in real time.

Mobile COLT can be installed into a Windows PC or Tablet and it functions on Google Chrome. When the webpage to start this application is opened, users are requested to put in the names of the coder and the target class before logging in. After logging in, they can choose whether or not they will use the recording function to start coding.

Table 2. Simplified coding categories of Mobile COLT.

\begin{tabular}{|c|c|c|c|c|c|c|c|c|c|c|c|c|c|c|c|c|c|c|c|c|}
\hline \multicolumn{2}{|c|}{ LANGUAGE } & \multicolumn{3}{|c|}{$\begin{array}{l}\text { PARTICIPANT } \\
\text { ORGANIZATION }\end{array}$} & \multicolumn{3}{|c|}{ CONTENT } & \multicolumn{2}{|c|}{$\begin{array}{l}\text { CONTENT } \\
\text { CONTROL }\end{array}$} & \multicolumn{4}{|c|}{ STUDENT MODALITY } & \multirow{2}{*}{\multicolumn{2}{|c|}{$\begin{array}{c}\text { MAT-TEXT } \\
\text { Text }\end{array}$}} & \multicolumn{2}{|c|}{\begin{tabular}{|l|l|} 
MAT- & MAT- \\
AUDIO VISUAL
\end{tabular}} & \multirow{2}{*}{\multicolumn{3}{|c|}{$\begin{array}{c}\text { MAT-SOURCE } \\
\text { Source }\end{array}$}} \\
\hline & & & ole & & & ning & & & & & & & & & & & edia & & & \\
\hline$\Xi$ & I & $\begin{array}{l}\text { 兽 } \\
0\end{array}$ & $\underline{\underline{z}}$ & है & 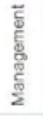 & $\begin{array}{l}\frac{\mathrm{g}}{8} \\
\frac{\mathrm{g}}{2}\end{array}$ & ह్ర & 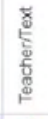 & $\begin{array}{l}\text { हूँ } \\
\text { 产 }\end{array}$ & $\begin{array}{l}\frac{2}{5} \\
\frac{5}{w}\end{array}$ & 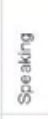 & 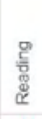 & $\frac{2}{3}$ & 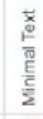 & 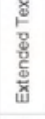 & $\frac{0}{3}$ & $\frac{\pi}{2}$ & 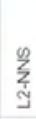 & 齐 & 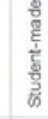 \\
\hline
\end{tabular}

Mobile COLT has the following distinctive features.

1. Users only need one tablet PC installed with Mobile COLT in order to record and code a class.

2. The result of the coding is instantly displayed at the end of a lesson.

3. The coding results can be revised even after the coding is completed.

4. More than one observer can use the coding application if their PCs are connected by Wi-Fi. 


\section{Implementation of lesson study with the use of mobile COLT}

Lesson study using Mobile COLT was started for teacher development in different levels of schools. The authors visited language classes of these schools five times in the year of 2016 and 2017 to observe and code the classes, and gave the teachers feedback as hints for the improvement based on the COLT analysis results. Table 3, 4, and figure 2 show the coding results of the visited classes. These results indicate that the degree of teaching improvement vary with different levels of school and teachers need to be informed of detailed effective teaching methods to implement the provided feedback in their classroom practices.

Table 3. Usage rate of L2(English).

\begin{tabular}{lccccc}
\hline \multicolumn{5}{c}{ 1st Clas: 2nd Clas 3rd Clas 4 th Clas 5 th Clas: } \\
\hline Elementary & $67 \%$ & $47 \%$ & $79 \%$ & $46 \%$ & $68 \%$ \\
Junior High & $78 \%$ & $48 \%$ & $29 \%$ & $29 \%$ & $65 \%$ \\
High & $87 \%$ & $55 \%$ & $89 \%$ & $93 \%$ & \\
\hline
\end{tabular}

Table 4. Usage rate of message-focused activities.

\begin{tabular}{lccccc}
\hline & 1st Clas: 2nd Clas 3rd Clas & 4th & Clas & 5th Clas: \\
\hline Elementary & $29 \%$ & $45 \%$ & $71 \%$ & $29 \%$ & $58 \%$ \\
Junior High & $47 \%$ & $94 \%$ & $9 \%$ & $21 \%$ & $48 \%$ \\
High & $52 \%$ & $55 \%$ & $64 \%$ & $51 \%$ & \\
\hline
\end{tabular}

Figure 2. Chang in teaching style of a junior high school teacher in a year.

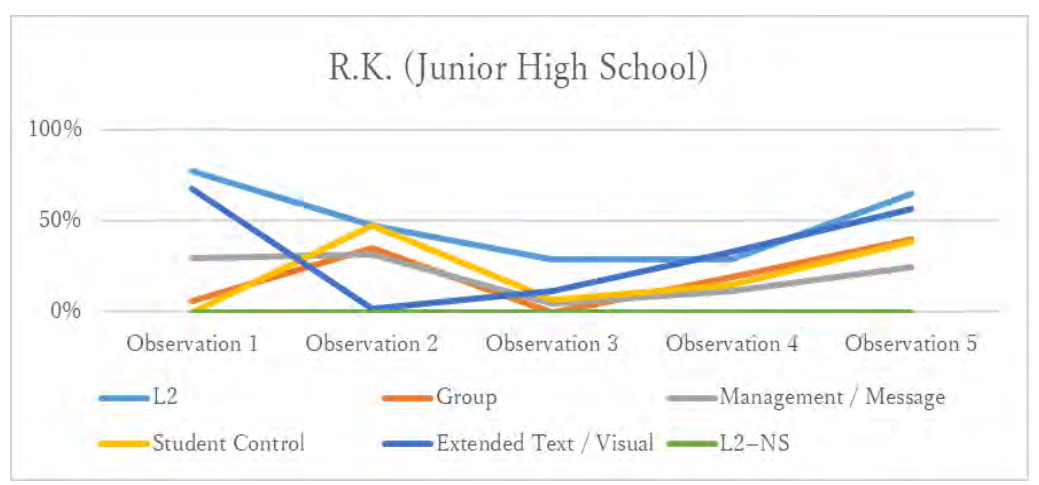

\section{Automation of mobile COLT}

When Mobile COLT is used in a classroom, a coder, who is well-informed on language teaching and COLT coding method, needs to accompany the teacher in the classroom. S/he helps the teacher with the COLT analysis by working on segmenting and coding the activities of a class while carefully observing them. This can only be done by trained coders, and it is one of the obstacles to diffusing the use of Mobile COLT among language teachers. Thus, in 2018, the authors have set out to develop a new version of Mobile COLT. It is designed to code a language class automatically without help of a coder. The automation process can be realized through the three steps. The first step is to transcribe the teacher's utterances in class using the latest Speech-to-Text technology. The second step is to extract key phrases like "Talk in pairs", "Read aloud", "Repeat after me", etc. from these transcribed utterances, and collate the combination of these phrases with the information on coding patterns stored beforehand in the server. The last step is to decide the length of the activity based on the information gained from the previous two steps and to confirm the validity of coding work considering the relatedness to the coded activities that AI has already learned. The Implementation of this automatic version of COLT will make a great contribution to language teacher development. 


\section{References}

Agawa, T., \& Takeuchi, O. (20 16). A new questionnaire to assess Japanese EFL learners' motivation: Development and validation. Annual Review of English Language Education in Japan (ARELE), 27, 1-16.

Ahlem, A. \& Spada, N. (2006). One size fits all? Recasts, Prompts and L2 learning. Studies in Second Language Acquisition, 28(4), 543-574.

Anno, H. (2003). COLT o mochiita kouritsushougakkoueigokatsudou no jugyoubunsekikenkyu [Study on class analysis of elementary school foreign language activities]. Celes Journal 3, 185-192.

Fernandez, C., \& Yoshida M. (2004). Lesson Study A Japanese Approach to Improving Mathematics Teaching and Learning. Mahwah, NJ: Lawrence Erlbaum.

Fujimori, K. (1990). Discourse analysis to COLT scheme ni yoru jugyoubunseki [Class analysis by discourse analysis and COLT scheme]. The JACET 29 ${ }^{\text {th }}$ Nationl Convention Book, 18-19.

Guilloteaux, M. J., \& Dörnyei, Z. (2008). Motivating language learners: A classroom-oriented investigation of the effects of motivational strategies on student motivation. TESOL Quarterly, 42(1), 55-77.

Nakatome, T. (1984) Konaikenshu o tsukuru: Nihon no konaikenshu keiei no sogoteki kemkyu [Developingkonaikenshu: a comprehensive study of management of Japanese konaikenshu]. Tokyo: Eidell Kenkyusho.

Panova, I. \& Lyster, R. (2002). Patterns of corrective feedback and uptake in an adult ESL classroom. TESOL Quarterly, 36(4), 573-596.

Spada, N., \& Fröhlich. (1995). Colt observation scheme: communicative orientation of language teaching coding conventions \& applications. NCELTR Publications.

Sugino, Koga and Kawashima. (2004). A Longitudinal study of English language activities at a kindergarten: focusing on shifts in instructional practices. ARELE, 15.

Takahashi, A., \& Yoshida, M. (2004). Ideas for establishing Lesson-Study communities. Teaching Children Mathematics, Vol. 10, Issue 9, 436-443.

Tanaka, H., \& Hiromori, T. (2006). The effects of educational intervention that enhances intrinsic motivation of L2 students. JALT Journal, 29(1), 59-80.

Yamada, Y. (1996). A case study of children's cross-cultural understanding in relation to the target language use. JASTEC Journal, 15, 13-26. 